\title{
Final Technical Report on DOE grant \#DE-FG05-87ER45316
}
A. Research Highlights
B. Publications
C. Professional Activities
Invited Talks at International Conferences
D. Degrees earned by students
E. Personnel
F. Research Collaborations 


\section{DISCLAIMER}

This report was prepared as an account of work sponsored by an agency of the United States Government. Neither the United States Government nor any agency thereof, nor any of their employees, make any warranty, express or implied, or assumes any legal liability or responsibility for the accuracy, completeness, or usefulness of any information, apparatus, product, or process disclosed, or represents that its use would not infringe privately owned rights. Reference herein to any specific commercial product, process, or service by trade name, trademark, manufacturer, or otherwise does not necessarily constitute or imply its endorsement, recommendation, or favoring by the United States Government or any agency thereof. The views and opinions of authors expressed herein do not necessarily state or reflect those of the United States Government or any agency thereof. 


\section{DISCLAIMER}

Portions of this document may be illegible in electronic image products. Images are produced from the best available original document. 


\section{A. Research Highlights}

During the tenure of the DOE grant \#DE-FG05-87ER45316 we have concentrated on equilibrium geometries, stability, and the electronic structure of transition metal-carbon clusters ("met-cars"), clusters designed to mimic the chemistry of atorns, and reactivity of homo-nuclear metal clusters and ions with various reactant molecules. It is difficult to describe all the research we have accomplished as we have published 38 papers. In the following, we outline briefly the salient features of our work and refer the reader to the papers on page 6-9 for details. We have given 46 invited talks at international conferences, and organized 8 international conferences/symposia during this period.

\section{(i) Designer Clusters: Building Blocks for a New Class of Solids}

Atomic clusters, due to their large surface-to-volume ratio and unique geometries, possess uncommon properties that depend sensitively on their size and composition. These include stability, reactivity, electronic structure, and optical and magnetic properties. It has been known that metallic clusters derive their stability from electronic as well as atomic shell closures. With this understanding, we proceeded to evaluate the stability of compound clusters $X_{n} Y_{m}$ where $n$ and $m$ represent respectively the number of $X$ and $Y$ atoms in the cluster. We varied $X, Y, n$ and $m$ in such a way that the total number of valence electrons correspond to one of the magic numbers $2,8,20$, $40, \ldots$ (i,e. numbers of electrons needed to fill one or more of the electronic shells of an otherwise jellium cluster) and the total number of atoms are sufficient to close the atomic shells.

Using the self-consistent field linear combination of atomic orbitals - molecular orbital (SCFLCAO-MO) theory and the density functional method, we optimized the geometry of $\mathrm{Al}_{13}, \mathrm{Al}_{12} \mathrm{C}$, $\mathrm{Al}_{12} \mathrm{Si}$, and $\mathrm{Al}_{13} \mathrm{~K}$ clusters. We studied their energetics and reactivity. The first three clusters were found to prefer the icosahedric symmetry and $C$ and $S i$ were found to occupy the central site of the icosahedron. On the other hand, $\mathrm{Al}_{13} \mathrm{~K}$ cluster had a geometry where $\mathrm{Al}_{13}$ remained icosahedric and $\mathrm{K}$ was found to occupy a three-fold site external to the icosahedron. The existence of these structures have now been verified in molecular dynamics simulations. The stability of $\mathrm{Al}_{12} \mathrm{C}, \mathrm{Al}_{12} \mathrm{Si}$, and $\mathrm{Al}_{13} \mathrm{~K}$ was substantially enhanced over that of $\mathrm{Al}_{13}$. The enhanced stability of $\mathrm{Al}_{12} \mathrm{C}$ and $\mathrm{Al}_{12} \mathrm{Si}$ over that of $\mathrm{Al}_{13}$ was caused by two factors: The number of valence electrons in the former equals 40 and correspond to a magic number. Secondly, the binding energies of AlC and AISi dimers are larger than that of $\mathrm{Al}_{2}$. In the case of $\mathrm{Al}_{13} \mathrm{~K}$, the stability is enhanced not only because we still have 40 valence electrons but the bonding between $\mathrm{Al}_{13}$ and $\mathrm{K}$ is ionic. Studies of reactions of $\mathrm{Al}_{12} \mathrm{C}, \mathrm{Al}_{12} \mathrm{Si}$, and $\mathrm{Al}_{13}$ with hydrogen revealed that while the former two clusters are unreactive, $\mathrm{Al}_{13}$ is quite reactive towards hydrogen.

The above finding has given way to a new class of problems where one envisages the possibility of assembling new materials with atomic clusters, not atoms, as building blocks. Since $\mathrm{Al}_{12} \mathrm{C}$ cluster is relatively "inert", it is possible to assemble these clusters into a fcc lattice where the weak interaction among them will keep them in "virgin" form. Although $\mathrm{Al}_{12} \mathrm{Si}$ clusters have been found (Seitsonen et al.) to disintegrate when brought together, $\mathrm{Al}_{12} \mathrm{C}$ clusters remain far more 
stable. Preliminary band structure studies of a model $\mathrm{Al}_{12} \mathrm{C}$ ciuster assembled crystal suggests that this may be a narrow gap semiconductor. Similarly, in a $\mathrm{Al}_{13} \mathrm{~K}$ cluster, $\mathrm{Al} \mathrm{l}_{13}$ and $\mathrm{K}$ remain as completely ionic species, $\mathrm{Al}_{13}$ and $\mathrm{K}^{+}$. Thus, if such clusters can be assembled into a crystal it is possible that like charges on $\mathrm{AI}_{13}$ units will keep them apart due to Coulomb repulsion. Thus, a super crystal with $\mathrm{Al}_{13} \mathrm{~K}$ as building blocks could be formed that could mimic the structure of $\mathrm{CsCl}$. This indeed will be exciting especially when we recall that $\mathrm{Al}$ and $\mathrm{K}$ are immiscible even in the molten state.

It must be emphasized that the above studies are yet to be confirmed by experiments. Efforts in this direction are currently under way at laboratories at the University of Tokyo, Johns Hopkins University and the Royal Institute of Technology. From the theoretical point of view, there is a lot to be done as well. For example, if the above clusters can be assembled into a crystalline form, do the individual clusters transform from one geometry to another, or do they completely disintegrate, or do they remain intact? Does such a cluster assembled crystal remain stabie or metastable. If it is the later, is the barrier high enough to withstand structural deformation? In addition to electronic and atomic shell closure, are there other criteria that can be used to enhance the stability of clusters used as building blocks? Our proposed research will explore some of these issues and is outlined in the next section in detail.

\section{(ii) Atomic Structure, Stability, and Electronic Pronerties of Metallo-Carbohedrenes}

Ever since the discovery of $\mathrm{C}_{60}$ and the associated fullerene materials there has been a constant search for new very stable clusters. One way to proceed is to investigate the stability of clusters made from fragments of very stable crystals. Refractory transition metal carbides and nitrides fall in this category since they are highly stable as evidenced by large cohesive energies and very high melting points. Most of them crystallize in a " $M X$ " $(M=T i, V, Z r$, etc.; $X=C$, $\mathrm{N})$ phase with a face-centered $\mathrm{NaCl}$ structure and are marked by strong covalent (partially ionic) bonds between the transition metal and carbon (nitrogen) atoms. There is practically no bonding between either transition metal or carbon (nitrogen) atoms. Further, the MX phases show marked deviations from stoichiometry. These features make their clusters where topology and composition can be varied over a wide range as a potential candidate for the new search.

About three years ago, Castleman and co-workers produced $\mathrm{Ti}_{\mathrm{n}} \mathrm{C}_{\mathrm{m}}$ clusters in molecular beams by reacting transition metal vapors with a variety of hydrocarbons. The ensuing mass spectrum showed a marked peak which was identified, by isotopic substitution, to correspond to a 20-atom cluster composed of $8 \mathrm{Ti}$ and $12 \mathrm{C}$ atoms. Based on selective chemical reactivity of the transition metal atoms with $\mathrm{H}_{2} \mathrm{O}$ and $\mathrm{ND}_{3}$, they proposed a caged dodecahedral structure composed of 12 pentagons. Subsequent theoretical investigations confinmed that the cluster indeed had a high binding energy of about $6.5 \mathrm{eV} /$ atom. Recent studies have revealed that the original structure can undergo substantial Jahn-Teller distortions which enhance its binding by several electron volts.

The discovery of a highly stable 20-atom cluster with a $\mathrm{Ti}: \mathrm{C}$ ratio of $1: 1.5$ is iatriguing since the bulk phase has a 1:1 composition. Even if the stability of the cluster could be reconciled with the high stability of TiC bulk, the existence of nondissociated $\mathrm{C}_{2}$ molecules and the cage 
structure are both unusual since the bulk has a compact structure with dissociated $\mathrm{C}$ atoms. Further, the original beams did not contain any clusters which would correspond to bulk fcc fragments. Recently, when the experimental group tried to make similar cluster containing titanium and nitrogen instead of carbon, the ensuing $T_{n} N_{m}$ clusters were all found to correspond to cubic fcc compact fragments. Since $\mathrm{N}_{2}$ molecule has a higher binding energy than a $\mathrm{C}_{2}$ molecule, it is not clear why met-cars which rely on $C_{2}$ molecular units for stability are not observed for the stronger $\mathrm{N}_{2}$ molecule.

The above experiments taised several questions. (1) What are the relative stabilities of the cubic and the met-car structures in carbides and nitrides? (2) What are the electronic bondings which characterize the met-car and the cubic arrangements, and do the met-cars represent a new family of metal-carbon structures? Further, why do the metal-carbon systems prefer met-cars while the metal-nitrogen clusters favor cubic structures? (3) Can the source conditions affect the formation of met-cars or cubic structures in the case of carbides?

We studied electronic structure and stability of metallo-carbohedrenes (met-car) and cubic structures containing $T i$ and $C$ or $N$ using the SCF-LCAO-MO density functional approach. We showed that while the met-car and the cubic structures have comparable binding energies per atom for the case of carbides, the cubic structures are more stable for metal - nitrogen systems. This change in behavior is shown to be related to the differences in the nature of electronic bonds which stabilize the two structures. By studying small $\mathrm{Ti}_{n} \mathrm{C}_{\mathrm{m}}$ and $\mathrm{Ti}_{\mathrm{n}} \mathrm{N}_{\mathrm{m}}(\mathrm{n}+\mathrm{m}<6)$ clusters, we identified these features and showed that the met-car and cubic arrangements represent two different families whose formation is governed by the composition of the beam. This is confirmed later by experiment.

We have examined the possibility that a new metallo-carbohedrene (met-car) $\mathrm{Ti}_{8} \mathrm{~N}_{4} \mathrm{C}_{8}$ containing $\mathrm{Ti}, \mathrm{N}$, and $\mathrm{C}$ could exist. Ab-initio self-consistent calculations carried out within the density functional scheme show that the $\mathrm{N}-\mathrm{N}$ bond in the new Met-Car cage is considerably larger than in a free $N_{2}$ molecule. The cage is therefore decorated by 4 strong $C_{2}$ and 2 weakened $N_{2}$ molecules and resembles a patched ball. An analysis of the binding energies reveals that the clusters is stable against-possible fragmentation and hence should be observable in experiments. This prediction awaits experimental confirmation.

\section{(iii) Reactivity of Metal Clusters with $\mathrm{H}_{2}$ and $\mathrm{NO}$}

The desire to achieve a fundamental understanding of heterogeneous catalysis has led to considerable interest in studying the interaction of $\mathrm{H}_{2}, \mathrm{NO}$, and $\mathrm{CO}$ with transition metal atoms, ions, and clusters. The central questions concern the nature and strength of bonding as successive gas molecules are allowed to decorate the cluster. Studies of $\mathrm{H}_{2}$ interaction with transition metal ions reveal that hydrogen binds molecularly and that several $\mathrm{H}_{2}$ molecules can be bound to a single cation. While the bond dissociation energies, defined as the energy gained in adding successive $\mathrm{H}_{2}$ molecules to a cation, decreases as the number of $\mathrm{H}_{2}$ 's increases for most transition metal atoms, it behaves anomalously for $\mathrm{V}$. In $\mathrm{V}^{+}\left(\mathrm{H}_{2}\right)_{n}$, the bond dissociation energies increase as n goes from 5 to 6 . 
We have calculated equilibrium geometries and bond dissociation energies of $\mathrm{M}^{+}\left(\mathrm{H}_{2}\right)_{\mathrm{a}}(\mathrm{M}$ $=\mathrm{Al}, \mathrm{Co}, \mathrm{Ni}, \mathrm{Cu}$, and $\mathrm{V})$ for $\mathrm{n}$ up to 6 using SCF-LCAO-MO method within the framework of Hartree-Fock-Möller-Plesset fourth order perturbation theory (HF-MP4) as well as density functional method, Both the theories predict that the binding of hydrogen to the ion is molecular and remains so even after other $\mathrm{H}_{2}$ 's are added to the cluster. The interaction of $\mathrm{H}_{2}$ with cluster ions is governed by charge polarization while that with neutral clusters and metal surfaces is governed by charge transfër from metal atoms to hydrogen.

The anomaly in the bond dissociation energies in $\mathrm{V}^{+}\left(\mathrm{H}_{2}\right)_{\mathrm{n}}$ was suggested to be due to change in the spin multiplicity of $\mathrm{V}^{+}$from the quintet to triplet for $\mathrm{n}=5$. Our studies based in HF-MP4 revealed that one of the $\mathrm{H}_{2}$ molecules was bonded weakly to $\mathrm{V}^{+}$in $\mathrm{V}^{+}\left(\mathrm{H}_{2}\right)_{5}$ ciuster than the other four molecules and that the preferred spin multiplicity remained as quintet. The anomaly could be explained by structural arguments alone. Recencly, other theoretical studies with more extensive basis sets but based upon density functional theory have found the spin triplet to be lower in energy than the quintet in $\mathrm{V}^{+}\left(\mathrm{H}_{2}\right)_{s}$. Following this study, we have repeated our calculations using the same limited basis but density functional theory and find the triplet to be indeed lower in energy, but reverse is true if one uses HF-MP4. These discrepancies point to the need for an elaborate quantum chemical study involving a higher level of correlation and an extended basis to determine the influence of correlation and basis set. This is particularly important in situations where the energy differences between different spin multiplicities is very small ( $\approx 0.1 \mathrm{eV}$ or less). We plan to pursue this problem not only for $\mathrm{V}^{+}$but other transition metal systems such as Sc.

The nature of dissociation of $(N O)_{n}(n=1,2)$ on neutral and cationic Ni clusters was studied using the self-consistent molecular orbital theory. The total energy surface was calculated using the UHF-MP4 level of theory. Unlike $\mathrm{H}_{2}$, nitric oxide is found to be molecularly chemisorbed on both neutral $\mathrm{Ni}$ atom and $\mathrm{Ni}^{+}$ion, but binds dissociatively on $\mathrm{Ni}$ clusters. The results are consistent with the experimental studies of nitric oxide interacting with transition metal cluster ions.

\section{(iv) Anomalous Spectroscopy of $\mathrm{Li}_{i} \cdot$ Clusters}

Although alkali metals are the flagships of the free-electron model, $\mathrm{Li}$ metal seems to be an exception to the rule. The electronic properties that characterize the non-free electron behavior of Li metal include (I) the asphericity of the Fermi surface, (ii) anomalous pressure dependence of the Knight shift, and (iii) the broadening of the soft $x$-ray emission and absorption edges. What is not clear is whether these discrepancies are manifestations of the semi-localized nature of the conduction electrons of the Li crystal or if they are rooted in the electronic structure of the atom itself.

A recent experiment on the photoelectron spectra of $\mathrm{Li}_{4}{ }^{-}$by Sarkas et al. suggests that $\mathrm{Li}$ clusters, after all, may not behave the same way as other alkali clusters do. These authors had earlier observed that the photoelectron spectra of $\mathrm{Na}_{4}{ }$ and $\mathrm{K}_{4}$ were similar and were both characterized by two broad peaks separated in energy by about $0.5 \mathrm{eV}$. In contrast, the photo 
detachment spectra of $\mathrm{Li}_{4}^{-}$are characterized by two very sharp peaks separated by an energy gap of about $0.1 \mathrm{eV}$. To understand the origin of this anomalous behavior, we have carried out SCFLCAO-MO calculations of the total energy surfaces of $\mathrm{Li}_{4}^{-}$and $\mathrm{Na}_{4}^{-}$using both the HF-MP4 and local density approximation. We show that the ground state of $\mathrm{Li}_{4}$ consists of two nearly degenerate isomeric structures - a spin doublet rhombus and a spin quartet tetrahedron. The sharpness as well as the narrow gap between the photoelectron peaks can be explained from the transitions between the spin doublet thombic (spin quartet tetrahedral) $\mathrm{Li}_{4}$ to spin singlet rhombic (spin triplet tetrahedral) neutral $\mathrm{Li}_{4}$. These transitions originate from an intricate interplay between geometry, electronic structure, and spin multiplicities of alkali clusters. This work establishes for the first time that photoelectron spectroscopy can identify the existence of metal cluster isomers.

\section{B. Publications}

Liu, Feng., Khanna, S.N., Magaud, L., Jena P., v. de Coulon, F. Reuse, Jaswal, S.S., He, X. G., and Cyrot-Lackmann, F. Magnetism of AlMn Quasicrystals, Phys. Rev. B. 48, 1295 (1993).

Niu, J., Rao, B.K., and Jena, P.: Niu et al. Reply, Phys. Rev. Lett. 70, 3837 (1993).

Antonelli, A., Khanna, S.N., and Jena, P.: Interplanar Relaxation at the (0001) surface of Be, Surf. Sci. 289, L614 (1993).

Vail, J.M., McMullen, T., and Meng, J.: Electronic Structure Determination of Light ImpurityPhonon Interaction in Solids, Phys. Rev, B49, 193 (1994).

Antonelli, A., Khanna, S.N., and Jena, P.: Atomic Clusters on Surfaces: Interaction, Structure, and Stability, Brazillian J. Phys. 24, 948 (1994).

Niu, J., Rao, B.K., and Jena, P.: Interaction of Hydrogen Molecules with metal Cluster Ions, in Shape Memory Materials and Hydrides, Eds. K. Otsuka, and X. Fukai (Elsevier, 1994), p. 1277.

Rao, B.K., Khanna, S.N., and Jena, P.: Atomic clusters: A System with Reduced Dimension and Novel Properties, in Proceedings of SSPFA '94, Ed. V.Z. Lozovski (NASU Institute of Semiconductor Physics, Kiev, 1994); p. 427.

Niu, J., Rao, B.K., Khanna, S.N., and Jena, P.: On the origin of Anomalous bond dissociation Energies of $\mathrm{V}^{+}\left(\mathrm{H}_{2}\right)_{\mathrm{n}}$ clusters, Chem. Phys. Lett. 230, 299 (1994).

Harms, A.C., Khanna, S.N., Chen, B., and Castleman, Jr., J.: Dehydrogenation Reactions in $\mathrm{Mg}^{+}\left(\mathrm{H}_{2} \mathrm{O}\right)_{\mathrm{R}}$ Clusters, Chem. Phys. 100, 3540 (1994).

Khanna, S.N. and Reddy, B.V.: Geometry, Stability and Properties of Metallo-Carbohederenes, Computational Materials Science 2, 638 (1994). 
Reddy, B.V. and Khanna, S.N.: Metallo-Carbohedrenes; A New Class of Metal-Carbon Assemblies, J. Phys. Chem. 28, 9446 (1994).

Niu, J., Rao, B.K., Jena, P., and Manninen, M.: Interaction of $\mathrm{H}_{2}$ and He with Metal Atoms, Clusters and Ions, Phys. Rev. B. 21, 4475 (1995).

Reuse, F.A. and Khanna, S.N.: Geometry, Electronic Structure, and Magnetism of Small $\mathrm{Ni}_{n}$ (n $=2-6,8,13)$ Clusters, Chem. Phys. Lett. 234, 77 (1995).

Khanna, S.N.: Formation of Mixed Metallo-Carbohedrenes, Phys. Rev. B 51, 10965 (1995).

McMullen, T., Meng, J., Vail, J.M., and Jena, P.: Quantum Diffusion of Muonium in Alkali Halides, Phys. Rev. B. $\underline{51}, 15879$ (1995).

Khanna, S.N., and Jena, P.: Atomic Clusters: Building Blocks for a New Class of Solids, Phys. Rev. B. $\underline{51}, 13705$ (1995).

Khanna, S. N., Janot, C., and Cyrot-Lackmann F.: Clusters and Aggregates : Applications to Quasicrystals, Proc. International Conference on Quasicrystals (Avignon, France, 1995).

Jena, P., Khanna, S.N., and Rao, B.K.: Atomic Clusters: Past, Present, and Future in Clusters and Nanostructured Materials, Eds. P. Jena and S.N. Behera, (Nova Scientific, N. Y., 1996), p. 1.

Jena, P., Khanna, S. N., and Rao, B. K.: Designing Clusters as Super Elements, Surf. Rev. and Lett. $\underline{3}, 993$ (1996).

Rao, B. K., Jena, P., Ray, A. K.: Anomalous Spectroscopy of $\mathrm{Li}_{4}^{\circ}$ Clusters, Phys, Rev. Lett. 76 , 2878 (1996).

Reddy, B. V., and S. N. Khanna : Structure and Stability of $\mathrm{Ti}_{n} \mathrm{~N}_{\mathrm{m}}$ Clusters, Phys. Rev. B $\underline{54}$, 2240 (1996).

Nayak, S. K., and Ramaswamy, R.: Solid = liquid transition in model $(H F)_{\text {I }}$ clusters, Mol. Phys. 89, 809 (1996).

Nayak, S. K., Khanna, S. N., Rao, B. K., and Jena P.: Atomic structure of Nb Cluster Isomers and their Role on Reactivity, Chem. Phys. Lett., 256, 588 (1996).

Jena, P., Khamna, S. N., and Rao, B. K.: Designing Clusters as Super Elements, Surface Review and Letters 3, 993 (1996). 
Jena, P., Khanna, S. N., and Rao, B. K.: Physics of Atomically Engineered Materials in Science and Technology of Atomically Engineered Materials, eds. P. Jena, S. N. Khanna, and B. K. Rao, World Scientific Publishers (Singapore, 1996), p. 9.

Liu, F., Mostoller, M., Kaplan, T., Khanna, S. N., and Jena, P.: A Cluster-Assembled Solid: First-Principles Study of $\mathrm{K}\left(\mathrm{Al}_{13}\right)$ in Science and Technology of Atomically Engineered Materials, eds. P. Jena, S. N. Khanna, and B. K. Rao, World Scientific Publishers (Singapore, 1996), p. 39.)

Khanna, S. N., F. A. Reuse, and S. Bemel: On the low Magnetic Moment of $\mathrm{Ni}_{13}$ Clusters in Science and Technology of Atomically Engineered Materials, Eds. P. Jena, S. N. Khanna, and B. K. Rao (World Scientific Publishers (Singapore, 1996), p. 379.

Nayak, S. K., Khanna, S. N., Rao, B. K., and Jena, R.: Solid-to-Liquid Phase Change and Fragmentation in Small Ni Clusters in Science and Technology of Atomically Engineered Materials, eds. P. Jena, S. N. Khanna, and B. K. Rao, World Scientific Publishers (Singapore, 1996), p. 289.

Nayak, S. K., Khanna, S. N., Rao, B. K., and Jena, P.: Structures and Binding energies of small $\mathrm{Ni}_{2}(\mathrm{n} \leq 23)$ Clusters in Science and Technology of Atomically Engineered Materials, eds. P. Jena, S. N. Khanna, and B. K. Rao, World Scientific Publishers (Singapore, 1996), p. 297.

Lin, P. C., Ray, A. K., Niu, J, and Rao, B. K. : On the choice of atomic basis sets for the study of chemisorption of bydrogen on aluminum, in Science and Technology of Atomically Engineered Materials, Eds. P. Jena, S. N. Khanna, and B. K. Rao, World Scientific, Singapore, 1996, p. 275.

Jena, P., Khanna, S. N., and Rao, B. K.: Atomic Clustets: Past, Present, and Future in Clusters and Nanostructured Materials, eds. P. Jena and S. N. Behera, Nova Scientific (New York, 1996), p.1.

Rao, B. K., Niu, J., and Jena, P.: Energetics of Metal-Hydrogen Clusters, in Clusters and Nanostructured Materials, ed. P. Jena and S. N. Behera (Nova Scientific, New York, 1996), p. 295.

Khanna, S. N.: Magnetism of Metal Clusters in Clusters and Nanostructured Materials, Eds., P. Jena and S. N. Behera (New York, 1996), p. 265.

Rao, B. K. : Role of electrons in atomic clusters, in Electrons in Solids: Experiment and Theory, Eds. K. Perzynska and L. Dobrzynski (Institute of Physics, Warsaw University Branch, Bialystok, 1996); p. 1.

Jena, P. and Khanna, S. N.: Physics of Cluster Assembled Materials in Proceeding of the Intemational Conference on Granular and Nanostructured Materials, Sendai, Japan. Mat. Sci. and Engineering A217/218, 218 (1996). 
Jena, P., Khanna, S. N., and Rao, B. K.: Stability and Electronic Structure of Cluster Assembled Materials in Cluster Assembled Materials, ed. K. Sattler (Trans Tech Publications, Zürich, 1996), p. 1.

Jena, P. and Behera, S.: editors. Clusters and Nanostructured Materials, Nova Scientific Publishers, New York, 1996.

Jena, P., Khanna, S. N., and Rao, B. K.: editors. Science and Technology of Atomically Engineered Materials, World Scientific Publications, Singapore, 1996.

\section{Professional Activities}

\section{Invitations to speak at Conferences}

\section{P. Jena}

International Symposiurn on "Local Order in Condensed Matter Physics", Jekyll Island, U.S.A., 1993.

International Workshop on Ultrafine Particles and Nanostructured Materials, Stockholm, Sweden, 1993.

NATO Advanced Study Institute on Nanophase Materials, Corfu, Greece, 1993.

International Symposium on Atomic and Nucleonic Clusters, Santorini, Greece, 1993.

3rd International Summer School, Jyvaskyla (a series of 10 lectures on clusters), Finland, 1993.

International Union of Materials Research Society Meeting, Tokyo, Japan, 1993.

International Conference on Hydrogen in Metals, Yalta (declined), Ukraine, 1993.

International Conference on Current Trends in Physics, Bombay (declined), India, 1993.

International Conference on Nanophase Materials, Davos, Switzerland, 1994.

March Meeting of the American Physical Society, Pittsburgh, PA, U.S.A., 1994.

First Russian Conference on Clusters, St. Petersburg (declined), Russia, 1994.

VII International Symposium on Small and Inorganic Clusters, Kobe, Japan, 1994.

International Workshop on Clusters and Nanostructured Materials, Puri, India, 1994. 
Workshop on Metallic Clusters, Trento, Italy, 1995.

DOE Workshop on Centers of Excellence Nanostructured Materials, Berkeley, CA, U.S.A., 1995.

School on Magnetism and Physics of Nanosystems, (a set of 3 lectures) Stockholm, Sweden, 1995.

NATO ASI on Large Clusters of Atoms \& Molecules, Erice, Italy, 1995.

NATO ASI on Stability of Materials, Corfu (declined), Greece, 1995.

International Symposium on Metastable, Mechanically Alloyed \& Nanoctystalline Materials, Quebec, Canada, 1995.

International Conference on Advanced Materials, (two talks) Cancun, Mexico, 1995.

International Workshop on Cluster Science and Atomic Engineering, Nan Daihe, P.R. China, 1995.

International Conference on Clusters and Granular Materials, Sendai, Japan, 1995.

Workshop on Magnetic Nanostructures on Metal and Semiconductor Surfaces, Halle, Germany, 1996.

70th Colloid and Surface Science Symposium, Potsdam, N.Y., U.S.A., 1996.

Workshop on Density Functional Theory and Condensed Matter Systems, Stockholm (4 lectures), Sweden, 1996.

International Conference on Theory of Atomic and Molecular Clusters, Fontana, Wisconsin,U.S.A., 1996.

International Conference on Frontiers in Materials Modeling and Design, Kalpakkam, India, 1996.

International Aerosol Symposium, Moscow, Russia, 1996.

- Twenty seminars/Colloquia in university/laboratories in U.S.A., Canada, Finland, Japan, Germany, India, and Sweden.

\section{S.N. Khanna}

First International Conference on the Theory of Atomic and Molecular Clusters, Leer, Oldenberg, Germany, 1993. 
International Symposium on Local Order in Condensed Matter Physics, Jekyll Island, U.S.A., 1993.

Symposium on the "Physics of Clusters" at the Southeastern American Physical Society Meeting in Columbia, South Carolina, 1993.

March Meeting of the American Physical Society at Pittsburgh, 1994.

77th Canadian Chemical Society Conference, Winnipeg, Canada, 1994.

International Workshop on Clusters and Nanostructured Materials held in Puri, India, Dec. 29, 1994 - Jan. 4, 1995.

Group Meeting on Non-uniform Magnetic Ordering in the Surface Region of Rare Earth Metals, Feb. 3, 1995, VCU.

5th International Conference on Quasicrystals, 22-26 May, 1995 Aviguon, France.

March Meeting of the American Physical Society, St. Louis, U. S. A., 1996.

- Six seminars/Colloquia in U.S.A., Canada, and France.

\section{B. K. Rao}

Gordon Research Conference on hydrogen-metal systems, 1993.

Third Interrepublic conference on hydrogen material science and chemistry of metal hydrides, Kiev, Ukraine, 1993, (declined).

Conference on current trends in atomic and molecular physics, Bombay, India, 1993.

First Russian Conference on Cluster Chemistry, St. Petersburg, Russia, 1994.

Conference on "Solid State Physics: Fundamentals and Applications," Uzhgorod, Ukraine, 1994.

International Workshop on Clusters and Nanostructured Materials, Puri, India, 1994.

March meeting of the American Physical Society, Indianapolis, U. S. A., 1996.

International Summer School on Electrons in Solids (2 talks), Bialowieza, Poland, 1996.

International Symposium on Metal-Hydrogen Systems, Les Diablerets, Switzerland, 1996.

- Five seminars/colloquia in tbree countries. 


\section{Conferences Organized}

International Conference on "Local Order in Condensed Matter Physics," Jekyll Island, 1993.

Gordon Research Conference on "Hydrogen-Metal Systems," Tilton, N.H. 1993.

Symposium on Atomic Clustets, American Physical Society, Southeastern section, Columbia, SC, 1993.

Focused Sessions on Clusters and Cluster-Assembled Materials, March Meeting of the American Physical Society, Pittsburgh, PA, 1994.

Symposium on Clusters and Cluster Materials, APS March Meeting, Pittsburgh, PA, 1994.

International Workshop on Clusters and Nanostructured Materials, Puri, India, 1994.

International Symposium on the Science and Technology of Atomically Engineered Materials, Richmond, VA, 1995.

International Conference on Theory of Atomic and Molecular Clusters, Fontana, Wisconsin, 1996.

D. Degrees earned by Students

B. V. Reddy - Ph. D. -1994

J. Niu - Ph. D. - 1995

E. Personnel Supported

S. K. Nayak

B.V. Reddy

H. P. Zheng

P. Jena

B. Waestberg

S.N. Klanna

J. Niu

B.K. Rao

\section{F. Research Collaborations}

C. N. R. S., Grenoble, France - Prof. F. Cyrot-Lacknann

I. P. E., E. P. F. L., Lausanne, Switzerland - Prof. J. Buttet

Helsinki University of Technology and University of Jyvaskyla, Finland - Profs. R. M.

Nieminen and $M$. Manninen

University of Manitoba - Prof. J. M. Vail 
Michigan State University - Prof. S. D. Mahanti University of Virginia - Prof. L. Bloomfield University of Texas at Arlington - Prof. A. K. Ray University of Arkansas at Little Rock - Prof. J. A. Darsey

Naval Research Laboratory - Dr. B. I. Dunlap

Pem. State University - Prof. A. W. Castleman, Jr.

Johns Hopkins Uniyersity - Prof. K. H. Bowen

University of Alabama - Prof. R. Kawai 